
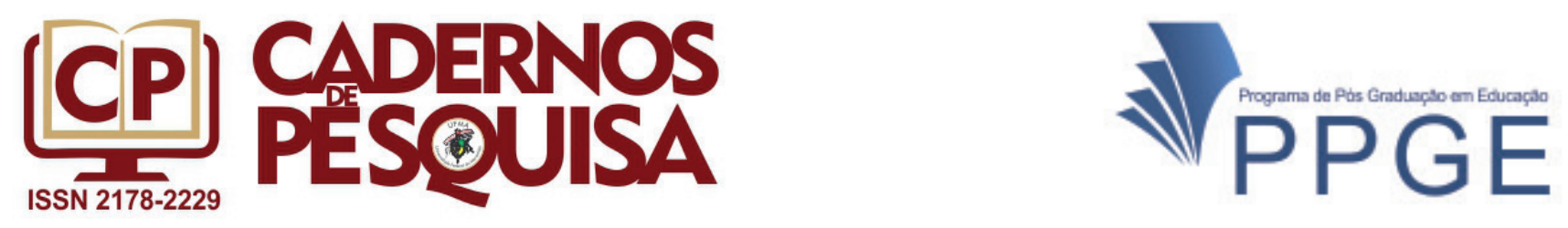

\title{
Formas da potência e estados artísticos na formação inicial e na docência em artes visuais
}

\section{Forms of potency and artistic states in teacher education and teaching in visual arts}

\section{Formas de la potencia y estados artísticos en la formación inicial y na docencia en artes visuales}

\author{
Carmen Lúcia Capra ${ }^{1}$ \\ ORCID: https://orcid.org/0000-0002-0185-7634
}

Luciana Gruppelli Loponte ${ }^{2}$

ORCID: https://orcid.org/0000-0002-0552-0529

\begin{abstract}
1 Licenciada em Educação Artística pela Universidade de Caxias do Sul (UCS), mestra e doutora em Educação pela Universidade Federal do Rio Grande do Sul (UFRGS). Atualmente é professora da Universidade Estadual do Rio Grande do Sul (Uergs). Lidera o Grupo de Pesquisa Flume Educação e Artes Visuais (Uergs/ $\mathrm{CNPq}$ ), tem experiência na área de Artes e se dedica à pesquisa sobre a formação docente em artes visuais com foco na atuação em escola. Integra o Núcleo Educativo MARGS-Uergs e participa do Grupo de Pesquisa Arteversa (UFRGS/CNPq). Tem atuado na promoção de ações de cunho artístico e educativo que permitam conversações entre ensino, pesquisa e extensão, a exemplo do Projeto Vincular (Núcleo Educativo MARGS - Uergs, Porto Alegre/RS), Exposição e Seminário Salas (Montenegro, RS), Dia do Desenho (Montenegro, RS), Bordado Livre na Praça (Monenegro/RS), participando de grupos experimentais de curadoria e prática artística.
\end{abstract}

2 Possui graduação em Licenciatura Plena em Educação Artística Hab. em Artes Plásticas pela Universidade Federal de Pelotas - UFPEL (1990), Mestrado em Educação pela Universidade Estadual de Campinas - UNICAMP (1998) e Doutorado em Educação pela Universidade Federal do Rio Grande do Sul - UFRGS (2005). Atualmente é pesquisadora e professora do Departamento de Ensino e Currículo da Faculdade de Educação da Universidade Federal do Rio Grande do Sul, atuando na graduação e no Programa de Pós-Graduação em Educação, na linha de pesquisa Arte, linguagem e currículo. É membro do Comitê de Ética em Pesquisa da UFRGS. Foi vice-presidente da FAEB (Federação de Arte-Educadores do Brasil) de 2006 a 2008 e coordenadora do Grupo de Trabalho (GT) 24 - Educação e Arte da ANPEd (Associação Nacional de Pós-graduação e Pesquisa em Educação) de 2008 a 2010, e membro do Comitê Cientifico da entidade de 2010 a 2015. Nos últimos anos, tem obtido financiamento do CNPq para suas pesquisas (Edital Universal 2007, 2010, 2013 e 2018). É líder do ARTEVERSA - Grupo de estudo e pesquisa em arte e docência (UFRGS/CNPq). Realizou estadia como Professora Visitante no Exterior Sênior com bolsa Capes, de novembro de 2018 a fevereiro de 2019, na Universidade de Lleida, na Espanha. Tem experiência na área de Educação, com ênfase em Ensino de Arte, atuando principalmente nos seguintes temas: ensino de arte, formação de professores, formação estética docente, arte e educação, gênero e artes visuais. 
Resumo: O texto parte de modos de relacionar-se com a arte, manifestados por professoras de artes visuais, seguindo com uma reflexão sobre as posições de professores em formação e em exercício em relação à arte. Apresenta uma reunião ensaística de ideias que fornecem meios para pensar as relações produzidas com a arte desde a formação docente inicial, como o caráter biográfico que compõe o estudo e as práticas de arte no curso de licenciatura. É feita uma argumentação sobre conceitos da filosofia, da filosofia da arte e da educação, como verdade e potência, por exemplo, a fim de elaborar contribuições para a formação docente em artes visuais. Ao final, em lugar de tomar como verdades exemplares as práticas legitimadas pelo campo artístico, defende-se que a docência possa adotar existências artísticas na forma da sua própria potência.

Palavras-chave: Licenciatura. Artes Visuais. Potência. Verdade.

\begin{abstract}
The text goes towards the ways to get related to art, these manifested by visual arts teachers, followed by a reflection about the positions of teachers under formation and those who are exercising their teaching concerning arts. It presents an essayistic meeting of ideas that provide means to think about the relations produced with art since the initial teaching formation, as the biographical character that composes the study and the art practices in the undergraduate course. An argument is made about concepts of philosophy, philosophy of art, and education, such as truth and potency, for example, in order to make contributions to teacher education in the visual arts. In the end, instead of taking as exemplary truths the practices legitimized by the artistic field, it is argued that teaching can adopt artistic existences in the form of its own power.
\end{abstract}

Keywords: Licentiate Degree. Visual Arts. Pontency. Truth.

Resumen: El texto parte de formas de relacionarse con el arte, manifestadas por profesores de artes visuales, y luego con una reflexión sobre las posiciones de los profesores en formación y en la ejercicio en relación con el arte. Presenta una reunión de ensayos de ideas que proveen medios para pensar sobre las relaciones producidas con el arte desde la formación docente inicial, como el carácter biográfico que compone el estudio y las prácticas artísticas en el curso de licenciatura. Se discute acerca de los conceptos de filosofia, filosofia del arte y la educación, como la verdade y la pontencialidad,por ejemplo,para hacer contribuciones a la formación del profesorado em las artes visuales. Al final, em lugar de tomar como verdades ejemplares las prácticas legitimadas por el campo artístico, se argumenta que la enseñanza puede adoptar existencias artísticas em la forma de su propio poder.

Palabras clave: Licenciatura. Artes visuales. Potencia. Verdad.

\title{
1 INTRODUÇÃO
}

A formação inicial de professores de artes visuais desenvolvida em cursos de licenciatura brasileiros deve atender às diretrizes da formação de professores para a educação básica e aos referenciais curriculares específicos para essa licenciatura (BRASIL, 2015; 2010). Esses são os primeiros e necessários regramentos que demarcam um tal campo de atuação profissional sobre o qual recaem várias atribuições sociais. Mesmo que para responder a elas sejam necessárias formas precisas, pois devem atender a certas metas, aqui propõe-se pensar sobre direções e sentidos que sejam inseparáveis de "potências e possibilidades" (AGAMBEN, 2013) na formação docente inicial em artes visuais, mesmo que haja a projeção de expectativas e normas a cumprir. O intento é o de refletir sobre as posições dos estudantes da licenciatura em artes visuais e docentes em relação à arte a partir de uma reunião ensaística de ideias que propiciem contribuições aos modos de pen- 
sar a relação entre professores e a arte. Para isso, este artigo pretende destinar atenção a alguns discursos que atravessam e conduzem a arte na licenciatura e na docência em artes visuais, como, por exemplo, a composição da licenciatura e alguns índices do contexto brasileiro, a história da arte e alguns modos de relação de professoras com o campo artístico. As questões abordadas têm aporte em autores como Bernardete Gatti, Carlos Skliar, Michel Foucault, Friedrich Nietzsche, Giorgio Agamben, Georges Didi-Huberman, entre outros e, embora as conexões entre eles visem pensar questões oriundas da docência em artes visuais, elas podem contribuir com reflexões para a formação docente em outros campos de conhecimento.

\section{ALGUNS ASPECTOS DA COMPOSIÇÃO DA LICENCIATURA EM ARTES VISUAIS}

A conjunção entre arte e educação na licenciatura em artes visuais, por mais que seja tomada como sua base, é um ponto sobre o qual existe uma tensão. Compor com uma e outra área na formação docente é pressupor alguns vínculos que, entre si, têm diferenças significativas: juntar arte e educação difere de vincular arte e educação, sendo que ambos contrastam muito com periodizar uma e outra. Contudo, para além do jogo de palavras (e não é intenção travar uma batalha por significados a partir da conjunção "e"), buscamos evidenciar os campos de força atuantes na formação docente em artes visuais em cursos de licenciatura. Ademais, se diferenças são reconhecíveis na conjunção entre arte e educação, é porque, de alguma forma, elas existem.

Analistas de licenciaturas brasileiras buscam verificar se esses cursos promovem a formação adequada para que professores atuem na educação básica. As pesquisadoras Gatti, Barreto e André (2011), analisando várias licenciaturas, constatam que a condição de formação de professores nas áreas específicas ainda demonstra a prevalência do modelo consagrado do início do século XX, conhecido pela fórmula (forma) "3 + 1": três partes de formação específica e uma a mais para obtenção da licenciatura. As autoras indicam, também, que falta aos currículos evidências de articulação entre as disciplinas de formação específica (conteúdos da área disciplinar, neste caso, a arte) e a formação pedagógica (conteúdos para formar a docência em arte), sendo que algumas licenciaturas promovem uma especialização precoce, tamanha a especificidade da abordagem sobre a área de formação. À boca pequena, diz-se nas faculdades de educação que o licenciado é bom em pesquisa, mas não, necessariamente, bom professor.

Além de serem pouco procuradas, as licenciaturas em geral são cursos de alta evasão. A desistência atinge cerca de $66 \%$, mesmo considerando que a oferta de vagas tenha sido ampliada nas universidades, conforme análise de Gatti (2015) sobre a formação docente em artes. Para a autora, os "conhecimentos educacionais em seus fundamentos e para o exercício da docência é proporcionalmente muito pequena em relação à formação disciplinar específica" (2015, p. 47). A estudiosa considera que são genéricas as ementas 
das disciplinas ligadas à educação e a suas práticas ao não indicarem a interdisciplinaridade entre os conhecimentos de área e as práticas educativas para a educação básica. Os fatores que contribuem para isso e citados pela autora, são: a) a permanência da cultura cristalizada da licenciatura como mero complemento do bacharelado, b) a adoção de perspectivas cientificistas fragmentárias sobre conhecimento, c) a desconsideração da área educacional como campo de conhecimento e desconsideração quanto aos aspectos relativos à formação de um professor que atuará junto a crianças, adolescentes e jovens nas escolas, d) a inexistência de um local onde a formação docente desenvolva-se de modo integrado (GATTI, 2015).

Especificamente sobre a formação artística da licenciatura em artes visuais, verifica-se que é assunto pouco tratado em publicações brasileiras. Conforme o levantamento de Silva (2010), no período entre 1989 e 2007, que abrangeu dissertações e teses, artigos publicados em periódicos especializados e em eventos da área da educação e das artes, há 175 publicações que tratam da formação docente. Dos diversos temas identificados no levantamento, chama a atenção que a formação artística na licenciatura em artes visuais é ausente do conjunto e que, ao menos naquele recorte de tempo, não tenha sido motivo de interesse ou suspeita dos pesquisadores. Já pelo levantamento realizado por Momoli (2016), sabe-se que no período entre 2008 e 2015 permanece a ausência da formação artística na licenciatura em artes visuais dentre as pesquisas. A análise foi realizada sobre os artigos publicados nos anais da Associação Nacional de Pós-Graduação e Pesquisa em Educação - ANPEd e da Associação Nacional de Pesquisa em Artes Plásticas - ANPAP. No rastreio das palavras-chave dos artigos, não houve referência à formação artística na licenciatura em artes visuais.

É possível observar alguns aspectos da arte que compõem a licenciatura em artes visuais por meio de matrizes curriculares de cursos universitários (CAPRA, 2015), onde são percebidos traços da formação tradicional do artista, originada nas primeiras academias europeias, como a seleção vestibular dar-se pela aplicação de uma prova de habilidade específica e o modo como as disciplinas sobre arte são distribuídas no currículo. As linguagens clássicas - desenho, sobretudo, mas também pintura, gravura e escultura - compõem o conjunto inicial de disciplinas do curso e desenvolvem-se em vários módulos. Diferentemente, tecnologias, como fotografia, cinema e recursos digitais, são componentes curriculares oferecidos na segunda metade da licenciatura, geralmente em disciplina única. Evidencia-se, com isso, que os currículos atendem antes às linguagens tradicionais do que ao que constitui a complexidade da visualidade dos dias de hoje e, além disso, estabelecem uma sequencialidade no conhecimento artístico que inicia sempre pelo desenho, em evidente hierarquização desse conhecimento em relação aos demais.

Gatti (2015) ainda contribui ao panorama com a sua observação sobre como os conhecimentos disciplinares estão distribuídos das licenciaturas em arte: os conhecimentos sobre a arte ocupam $65,9 \%$ do currículo, enquanto que são destinados $12 \%$ da carga ho- 
rária às metodologias e práticas de ensino. Essa defasagem, entretanto, não é prioridade da Licenciatura em Artes Visuais. Os percentuais em outras licenciaturas são, respectivamente: Biologia, 78,8\% e 7,5\%; História, 73\% e 8,5\%; Língua Portuguesa, 59,5\% e 7,5\%; Matemática, $53 \%$ e $11 \%$.

A mesma pesquisa aponta outros índices preocupantes a respeito do baixo número de professores habilitados e que trabalham na área em que atuam: em História são 34,3\%, enquanto que em Física são 16,9\%. No Rio Grande do Sul, conforme o Censo do Professor (BRASIL, 2007), o número de professores com formação superior que lecionam Arte (somados ensino fundamental e médio) é 8.504 e, conforme os dados do Censo Escolar de 2014, no estado do Rio Grande do Sul há 10.046 estabelecimentos de ensino, considerando instituições estaduais, federais, municipais e particulares. Se cada instituição deve ter ao menos um professor de arte, naquela época faltavam em torno de 1500 profissionais de Arte.

\section{VERDADES EM TORNO DA ARTE E DA COMPOSIÇÃO DA DOCÊNCIA EM AR- TES VISUAIS}

Para iniciar a reflexão sobre as posições que estudantes e docentes de artes visuais assumem em relação à arte, citamos o que disseram algumas professoras de artes visuais sobre a sua relação com o campo artístico. São modos ou expressões que existem e persistem no que é comentado em encontros onde se reúnem pesquisadores, professores formadores, estagiários e professores de arte em escola. Compondo cenas complexas da escola e dos problemas da profissão, os ditos transparecem as relações das professoras com a arte: "tenho saudade de desenhar, mas, dando aula, não dá", "guardei todas as minhas coisas [de fazer arte], não uso mais nada", "professor que faz arte é mais sensível com seus alunos", "estou me aposentando e vejo que não consegui ensinar arte mesmo", "todo professor teria que ter uma produção como artista".

Desse conjunto, observamos que a relação das professoras com a arte caracteriza-se pela dificuldade, muitas vezes abrindo mão dela. Também é uma tal arte que não encontra condições de ser atingida na escola e, sob a aparência de uma recomendação, fazer arte como artistas qualificaria o tratamento dado aos alunos. É um conjunto complexo que incentiva perguntar: que arte é essa, difícil de ser feita por quem dá aulas e difícil de ser verdadeiramente ensinada na escola, mas que aprimoraria a docência? O que ocorre entre a docência e as artes visuais que parece torná-las incompatíveis? Ao invés de focar nas dificuldades da profissão - o trabalho com elevado número de turmas e escolas, os problemas escolares que tomam o espaço da própria vida e a situação sempre instável da arte na educação regular -, interessa pensar sobre as práticas que põem em relação a arte e a docência em arte, presentes nos dizeres das professoras.

Para pensar sobre tais relações, adotamos inicialmente o questionamento de Nietzsche (2012) sobre a instituição das verdades. No entender do filósofo, a dedicação à ver- 
dade obscurece o nosso medo sobre o desconhecido, uma vez que não importa somente conhecer a verdade, mas, sobretudo, o efeito de segurança que a verdade proporciona. Ter o verdadeiro conhecimento é como estar em um solo firme e de apoio estável, mesmo quando o conhecido seja verificado por instâncias pouco abrangentes como familiaridade, o "mundo interior" do homem ou seus "fatos da consciência" (NIETZSCHE, 2012, §355).

Quando o conhecimento tem como "afeto de comando" a vontade do homem, a vontade de verdade gera um estado semelhante ao "sentir-se em casa" (NIETZSCHE, 2012, §347) que restringe a vontade de vida. A vida, para o filósofo, é o lugar da experimentação, do improviso, da possibilidade e do devir, e a sensação proporcionada pela verdade tanto institui deveres e crenças, quanto acomoda os movimentos do pensamento que produzem outros conhecimentos. Nietzcheanamente, então, não é possível adotar nem a essência das coisas e nem as certezas, pois a verdade é como uma pausa breve no movimento constante do pensamento e da vida.

Existe, contudo, um gosto em acreditar que há um início das coisas e que lá, na sua origem, tudo começaria em estado de perfeição. No contexto que viemos abordando, arte, docência em arte, escola e aula de Arte teriam uma essência ou um início exemplar. Foucault diria, porém, que no presumido começo histórico das coisas há um sentido caricatural e irônico (FOUCAULT, 2001) e, por isso, não se podem admitir verdades absolutas. O começo das ideias que está no imaginário sobre uma verdadeira ou ideal maneira de relação com a arte, por exemplo, não leva em conta que o mundo das coisas ditas e caras para nós conheceu, nas palavras de Foucault (2001), todo o tipo de lutas, invasões e astúcias na sua própria constituição. Apesar de pretenderem uma tal arte, conforme os dizeres das professoras, não há um início nem uma verdade para a relação com a arte na docência, pois sempre ocorrem desvios e acidentes na composição da história dessa verdade.

A história da arte é um bom exemplo para pensar, pois é um dos pilares adotados na formação desenvolvida na licenciatura em artes visuais. Sobre a história e a sua instituição como verdade, Foucault (2001) avalia que

[...] a questão da verdade, o direito que ela [a história] se dá de refutar o erro de se opor à aparência, a maneira pela qual alternadamente ela foi acessível aos sábios, depois reservada apenas aos homens de piedade, em seguida retirada para um mundo fora de alcance, onde desempenhou ao mesmo tempo o papel de consolação e de imperativo, rejeitada enfim como ideia inútil, supérflua, por toda parte contradita - tudo isto não é uma história, a história de um erro que tem o nome de verdade? A verdade e seu reino originário tiveram sua história na história. (FOUCAULT, 2001, p. 19. Grifo nosso).

Olhar com atenção para a história como um regime capaz de instaurar verdades pode dar a conhecer o que ocorreu nas lutas entre os discursos e as resistências a eles. Identificar as circunstâncias dos embates que compõem a história finalizada possibilitaria 
conhecer e reconhecer o jogo causal das dominações ou os sistemas de submissão que constituem as relações sociais, pois elas mesmas fazem-se sob autorizações e combates entre forças que ora enfraquecem, ora recobram o seu vigor. O reino originário da verdade, portanto, tem uma história onde atuam diversos episódios e acasos.

Em relação mais próxima do exposto com a arte, trazemos, a partir da proposição de Didi-Huberman (2013a), o jogo presente na disciplina história da arte a partir do o seu nome, onde atuam duas dimensões simultâneas. Primeiro, a dimensão genitiva objetiva de "história da arte", onde a história tem a arte como objeto ou onde a arte propõe-se como objeto ao olhar da história. Diferente, a dimensão genitiva subjetiva da mesma sentença posiciona a arte como sujeito de uma história, isto é, a história narra o desenvolvimento dos objetos de arte ou narra a história que a arte, como sujeito, tem. Segundo o autor, essa diferença de perspectiva causa um "incômodo teórico" e uma contradição constitutiva que funda a disciplina, fazendo com que seu estudo combine períodos e estilos, dados pelo olhar da história sobre a arte, com a análise dos objetos da arte, descrita em seu próprio desenvolvimento. Considerando que essa diferença é ignorada no estudo da arte em cursos de graduação, mostra-se importante detalhar o tema e considerar que efeitos produz para a docência em formação ou em exercício.

Ernst Gombrich (1909-2001), um historiador austríaco da arte, cujo livro "A História da Arte" (1993) é um dos mais usados nas graduações em artes visuais no Brasil, emprega a cronologia progressiva nos capítulos que vão dos "estranhos começos" da pré-história, à arte experimental da primeira metade do século XX. No decorrer do livro, porém, o texto desloca-se com naturalidade entre termos estilísticos e temporais e a análise estética de obras. Essa combinação se mantém oculta no que genericamente se entende como história da arte, então, é interessante avaliar que:

Muitas vezes essas duas acepções da história da arte são confundidas ou minimizadas, na certa por se imaginar uma disciplina objetiva que falaria inteiramente em nome de uma prática subjetiva. Evidentemente não é o que acontece. A história da arte no sentido subjetivo é com muita frequência ignorada pela disciplina objetiva. (DIDI-HUBERMAN, 2013a, p. 52).

A problematização realizada por Didi-Huberman acerca do tratamento da arte como objeto ou como sujeito da história perturba um dos campos menos questionados do conhecimento sobre a arte na formação docente, permitindo reconhecer forças que vigoram nesse campo disciplinar e outras que são ignoradas. Estimulante, contudo, é a insurgência de uma abertura para narrativas da arte, com as quais os envolvidos com o campo disciplinar podem vir a atuar com e sobre elas, produzindo as aberturas nesse sistema. Com a possibilidade de colocar outras forças em cena, seria possível que elas saltassem "dos bastidores para o teatro, cada uma com seu vigor e sua própria juventude” (FOUCAULT, 2001, p. 23), emergindo disso outras verdades. 
A história da arte ainda fornece outra prática considerável que é o seu caráter biográfico, fundado por Giorgio Vasari em 1550, na obra "As Vidas dos Artistas". Trata-se de um compêndio que explica hierarquicamente as lides da arquitetura, da escultura e da pintura da época e segue contando a vida de mais de uma centena de artistas. Para Didi-Huberman, recebemos de Vasari o legado do "fascínio pelo elemento biográfico" e uma

[...] imperiosa curiosidade em relação a essa espécie de indivíduos "distintos" - em todos os sentidos do termo - que são os artistas, a ternura excessiva ou, ao contrário, a mania do julgamento clínico quanto a seus menores atos e gestos. (DIDI-HUBERMAN, 2013a, p. 113).

Mesmo que Vasari ocupe o lugar de "verdadeiro patriarca e Pai da Igreja da história da arte" (DIDI-HUBERMAN, 2013a, p. 71), seria importante deslocá-la da abordagem pessoal do historiador e dos artistas. Uma vez que o modelo biográfico fundador estabeleceu um jogo sutil, onde regras e licenças ditam o que é melhor ou pior (DIDI-HUBERMAN, 2013a), ele funciona também como um fornecedor de exemplos que, de forma distintiva e minuciosa, é aplicado aos artistas e a quem aspira sê-lo.

Normalmente, contudo, é por exemplos que se dá o modo de estudar a arte nas disciplinas teóricas, poéticas e também pedagógicas nos cursos de licenciatura, onde artistas e obras são motivos para conhecer, entender, fazer e ensinar arte. Além de comporem um conjunto de intenção estimulante, os exemplos também podem imprimir um modo de agir, sugerindo aos licenciandos fazer arte como fizeram ou como fazem hoje, os artistas. Nesses casos, é necessário cuidar, porque a inspiração que vem de exemplos biográficos pode adquirir uma distinção emblemática e canônica.

Agamben (2013) faz uma diferença entre exemplo e exemplar. Os exemplos são "seres-ditos" que pertencem a classes e gêneros, enquanto que um exemplar é uma singularidade que não tem essência, é uma modalidade entre todas as modalidades possíveis. Os exemplos da arte chegam aos cursos de graduação pela referência ao que é fornecido por alguma parte do sistema da arte, como publicações, exposições e materiais educativos desenvolvidos por museus. As formas da história da arte (a sequência estilística e histórica e o viés biográfico), as exposições individuais, as curadorias autorais e os percursos dos artistas têm em comum um elemento distintivo e individual que gera efeitos no modo como a arte vai sendo descrita, classificada e articulada no curso universitário que prepara professores.

Acomodar a arte em um funcionamento calcado em exemplos faz com que eles não somente produzam distinção, mas que constituam "comunidades puras" (AGAMBEN, 2013) e descrevam, a cada vez, certos modos de ser e de operar com a arte. Como os exemplos podem apenas ser definidos pelo que se diz sobre eles, ao ocorrer isso, já não o são, são espaços vazios que perderam a potência existente em relação (e não em separação) a uma vasta gama de modos de ser. "Já ditos" pelo sistema e reconhecidos na formação de pro- 
fessores, os cânones propostos pela esfera disciplinar da arte podem vir a ser novamente afirmados nas aulas de arte na escola.

É certo que não há como formar professores prescindindo dos domínios que tecem as elaborações teóricas, poéticas e pedagógicas sobre a arte e não é o caso de condenar os modos como vem sendo tratada a arte na licenciatura e, por decorrência, no exercício docente. $\mathrm{O}$ que emerge nos ditos das professoras de artes visuais, portanto, é o jogo das verdades, das autoridades e das autorizações que compõem o campo artístico e que é continuado pelo campo educacional. E não é apenas uma inquietação sobre a separação entre a atuação artística e a docente, mas da instalação de uma incompatibilidade e a localização da arte em uma espécie de metafísica tanto desejada, quanto inacessível. Em conta disso, parece ser importante modular o tom restritivo de verdade que vem do campo organizador da arte e o efeito que isso produz em docências que não encontram condições para fazer arte exemplarmente ou que não têm autorização para assumir-se como um exemplar em sua existência artística.

Assim é possível compreender que as autorizações estabelecidas caracterizam e localizam os professores em relação à arte e em relação a si mesmos. O sujeito da docência em artes visuais que foi apresentado por frases bem conhecidas no âmbito docente é aquele impedido de produzir arte, que está afastado do que seria a arte ideal ao ensino escolar e, paradoxalmente, o que deve produzi-la para qualificar a sua atuação. Inquieta muito constatar que a arte passe de uma arte desejada, prescrita ou devida, para algo tornado irrealizável e utópico. Estão em funcionamento aí práticas distintas, no sentido foucaultiano, entre a docência e a arte, como se a arte tivesse uma utilidade para além do que a constitui ou como se o manejo da arte na educação escolar fosse um trabalho menor, porque, dando aulas, professores não exercem o fazer legítimo da arte.

A impossibilidade, a obrigação e a arte irrealizável seriam impedimentos ou incapacidades dos os professores? Por outro lado, seriam efeitos de governo ou dominação sobre eles? Para Foucault (1993), o governo dá-se pelo modo como os indivíduos são conduzidos e conhecidos por outros, ligado ao modo como os indivíduos conduzem-se e conhecem a si próprios. Na dominação constituinte das práticas sociais, há uma diferença de valores que se repete ininterruptamente, compondo cuidadosos procedimentos e distribuindo obrigações e direitos. É propriamente um ritual que "estabelece marcas, grava lembranças nas coisas e até nos corpos" e gera dívidas (FOUCAULT, 2001, p. 25), o que ressaltamos neste ensaio de análise de modos artísticos de ser na docência em artes visuais.

É preciso notar, contudo, que as regras que incidem violentamente sobre os sujeitos são vazias e não finalizadas. Se servem a esta ou àquela ordem, pois não existem desde sempre, as regras também "podem ser burladas ao sabor da vontade de uns e de outros" (FOUCAULT, 2001, p. 25). Os combates e as dominações ocorrem no campo discursivo e cabe a quem pretende reagir às coerções forçar a sua mudança de direção, não para 
preservar-se ou apreender o mundo dado, mas para permitir que nos guiemos no mundo (VEYNE, 1998).

\section{ARTE COMO POTÊNCIA NA DOCÊNCIA EM ARTES VISUAIS}

A ideia de potência trabalhada por Agamben (2015a, 2015b, 2014, 2012) também subsidia o ensaio analítico da relação de professores de artes visuais com a arte, conforme o que vem sendo comentado por quem dá aulas de Arte e que tem a ver com poder, não poder ou mesmo dever ter determinadas relações com a arte.

No texto "Sobre o que podemos não fazer", o filósofo expõe que uma operação de poder é "uma separação dos homens daquilo que podem, ou seja, da sua potência" (AGAMBEN, 2014, p. 71). O impedimento das forças ativas do homem ocorreria por duas vias: quando não há condições para o seu exercício ou quando o exercício das forças ativas é proibido. Nos dois casos, a expressão mais opressiva e brutal do poder em ação "separa os homens da sua potência e, desse modo, torna-os impotentes" (AGAMBEN, 2014, p. 71).

Todavia, há uma operação de poder sobre a potência dos homens que é mais dissimulada e de atuação mais tênue, mas não menos eficaz, pois não opera por meio de impedimentos parciais ou totais das condições para ou das proibições sobre. Dessa vez, a operação de poder visa aquilo que o homem pode não fazer.

O que significa dizer "eu posso", para além de um saber específico ou de uma habilidade especial? Não se trata nem de uma tal faculdade, nem de um saber fazer, porque, nessa sentença, o sujeito passa à frente da mais exigente e inevitável experiência, a da potência. Portanto, dizer "eu posso" põe o sujeito em jogo, pois, tendo adentrado em nós o vocabulário da potência, deixamos de perceber que o problema fundamental aí contido (e apontado por Agamben), é que a posse de uma faculdade pelo sujeito está separada do ato da potência. Assim, o sujeito que detém uma tal faculdade é autorizado a exercitar o ato pertinente àquela faculdade. Ensaiando isso no contexto apresentado, onde se observa a separação entre a faculdade (artística), o sujeito que a possui e o posterior ato (artístico), temos os impedimentos para a arte acontecer na vida docente de professoras que, em contraste, também carregam o aconselhamento de serem artistas para outras finalidades que não só o fazer da arte.

Para os gregos arcaicos, a sensibilidade ou a inteligência não eram consideradas como faculdades de um sujeito, pois não era possível dizer que elas deixassem de existir no estado "de repouso". No caso da sensibilidade, por exemplo, "A própria palavra aisthesis é, em sua forma, um nome de ação em -sis, que exprimia uma atividade real. Como pode, então, uma sensação existir na ausência de sensação, existir uma aisthesis no estado de anestesia?" (AGAMBEN, 2015b, p. 245). Seguindo a mesma indagação, se a inteligência fosse apenas uma faculdade de posse do sujeito, ela teria sua evidência somente na realidade do ato inteligente. 
"Saber fazer" e "ter uma faculdade" insinuam a existência de um sujeito que possui (um saber) ou que pode (fazer). É aí que a faculdade distingue-se da atividade onde é exercida e, também, onde a faculdade condiciona o ato, de modo que este passe a ser atribuído a um sujeito (AGAMBEN, 2015b). A título de exercício: sugerir que pode fazer arte quem tem o saber da arte é condicionar o ato artístico ao sujeito que tem essa faculdade. "Saber arte" diferencia-se do "fazer arte", e o primeiro, como faculdade, é condição para o segundo. Quando se fala do sujeito que tem um dom artístico, uma ideia repetida tanto em cursos de ensino superior como na educação básica, está demonstrada a condição do sujeito para exercer a arte, a separação e a condição entre dom e arte. Quando essa posse é julgada como inexistente, muitos afastam-se da prática artística.

A potência, contudo, não pode ser atribuída como um direito ou uma propriedade do sujeito, porque uma potência não pode ser possuída como uma faculdade. Essa relação se desprende da noção moderna e disciplinar de sujeito, considerado como possuidor uma consciência autorreflexiva, que seria o centro de imputação das faculdades e dos hábitos (AGAMBEN, 2015b). Ao sugerir como se relacionariam potência e liberdade, esta sendo uma propriedade do sujeito, então, Agamben propõe o seguinte: "Autenticamente livre, nesse sentido, seria não quem pode simplesmente cumprir este ou aquele ato, mas aquele que, mantendo-se em relação com a privação, pode sua impotência" (AGAMBEN, 2015b, p. 250). Não existe potência somente na própria atividade porque, na concepção aristotélica, a potência admite o não-fazer e o não-ser, onde estaria a liberdade em ato, fora da lógica binária que fica às voltas do sujeito e da sua atividade.

A potência como possibilidade de não é o mesmo que a disposição de uma privação, o que Agamben (2015a; 2015b) explica pelo arquiteto e pelo pianista: a potência de construir e de tocar existe mesmo que não estejam construindo e tocando. Quanto mais executam projetos e concertos, mais alimentam aquela potência, ao mesmo passo que a potência não se desfaz no estado de inoperância. Arquiteto e pianista podem não construir e não tocar como estados da potência.

A amplitude e a privação, como formas da potência humana, atribuem uma "mística como fundamento secreto" do saber e do agir do homem. Mesmo que o homem seja "o senhor da privação porque mais que qualquer ser vivo ele é, em seu ser, destinado à potência", significa dizer também que todo o seu poder agir "é constitutivamente um poder não agir, todo o seu conhecer, um poder não-conhecer" (AGAMBEN, 2015b, p. 249). Potência e impotência copertencem à potência, o que vai evidenciando um conceito de constituição ambivalente, porque aquele que existe no modo da potência "pode sua própria impotência, e só desse modo possui sua potência. Ele pode ser e fazer porque se mantém em relação com seu não-ser e não-fazer" (AGAMBEN, 2015b, p. 249). A título de exemplo, significa que a sensação como potência é constitutivamente anestesia, o pensamento como potência é não-pensamento, a obra, em potência, também é inoperosidade. 
Resta acrescentar ao problema da potência a relação com a vontade e a necessidade do sujeito. Agamben entende que reduzir a potência à vontade e à necessidade seria propriamente evitá-la, a exemplo da incômoda passagem entre "o que você pode" e "o que você quer" ou "o que você deve". O vocabulário da potência penetrou profundamente no sujeito, a ponto de colocá-lo em jogo: se é o sujeito que pode, que não pode ou que deve, é porque nele está o foco. Nos termos da potência, todavia, inexiste sujeito, há só potência humana, onde é potente o que ocorre pelo ato do qual se diz que tem potência e onde o campo de possibilidade assume operosidade e inoperância como atos da potência de cada coisa.

Quando uma professora "não faz arte", é comum que isso seja entendido como a incapacidade de quem não quer ou não pode fazê-la, em um movimento discursivo que se dirige à vontade ou à necessidade da professora. A impotência remetida ao sujeito, corrobora a racionalidade moderna a respeito do indivíduo, que neste caso, é centro e alvo da transferência da potência da esfera do pensamento para a esfera da individualidade. Propomos pensar sobre o poder fazer arte de professoras, deslocando-o da habilidade artística, da vontade ou de qualquer tipo de autorização. Na perspectiva da potência que se apresenta, o poder de não (ou inoperância) não aniquila a potência ou torna o sujeito impotente, mas é uma atitude de privação. Desta forma, não perde a potência de arte uma professora que não produz arte; a inoperância artística é uma atitude e um estado possível da potência da arte. A revisão do sentido do que se diz sobre poder ou não poder fazer arte, retira a centralidade da individualidade das professoras, rejeita o julgamento da vontade delas e desassocia a capacidade individual da produção artística.

Pelo exposto, buscamos uma via de aproximação à questão delicada e substancial da arte na formação e na atuação docente em artes visuais, onde os modos de existência difundidos pelo campo artístico, como os modos autoral e biográfico, que autorizam certas práticas e identidades, funcionam como verdades ou imperativos subjetivos para a relação de professores com as artes visuais, inclusive para sua atuação com outros, em escolas. O artista e a arte feita por ele constituem o âmago do estudo da arte na licenciatura, o que é aparente no rumo da formação artística dos licenciandos nos ateliês, nas disciplinas de história e crítica da arte (biograficamente tonalizadas) e no modo como as abordagens metodológicas de ensino de arte retomam o discurso artístico, calcado no dizer institucional da arte e do artista. Propomos que o lugar que está por ser ocupado por professoras e professores de artes visuais é outro, diferente do artista e do discurso institucional da arte que o valida, em uma subjetividade que precisa escapar da centralidade do sujeito, pois seria um lugar em relação à arte a partir da educação e do convívio com crianças, jovens e adultos.

Para desenvolver algumas linhas de pensamento sobre educação, elegemos o enfoque dado por Skliar (2014), sobre o educar como colocar no meio, fazer coisas juntos, entre os que fazem e entre os outros. Na ideia do autor, educar é constituir outras vidas para as próximas gerações, especialmente porque a elas estaria posta a tarefa de ir adiante da 
preservação de heranças e identidades já existentes. A possibilidade de ensinar aos jovens a afirmação da vida

[...] só encontra certo tipo de resposta se a educação é pensada, não sob a urgência mesquinha de uma obrigação moral a ser padecida, mas como aquele tempo e espaço que abre uma possibilidade à presença do outro e, sobretudo, à existência, toda existência, qualquer existência de qualquer outro (SKLIAR, 2014, p. 196. Grifo nosso).

Para que toda existência tenha presença e lugar na educação, o autor avalia ser preciso afirmar a responsabilidade educativa na intenção de confrontar as "inovadoras" propostas que buscam decifrar a juventude, mas pensamos que isso também se aplica aos professores. Afirmar a vida seria, para estudantes e docentes, pôr algo em comum entre as experiências, sem simplificar, nem reduzir, nem mesmo assimilar uma experiência na outra (SKLIAR, 2014), mesmo que exista a dimensão do ensino e da aprendizagem dos conteúdos fundamentais ao campo.

À vista da concepção exposta, podemos pensar nos termos da docência em artes visuais e nas possibilidades de existências artísticas produzidas para professoras e professores (com os futuros alunos) que vão além de uma relação já delineada pelo exemplo da esfera da arte. Se professoras desistem de desenhar e se retiram da vida "as coisas" da arte por impotência ou impedimento, mesmo que essa relação seja permeada por motivos como a falta de tempo, as tarefas excessivas do trabalho ou a suposta insuficiência da arte feita na escola, está demonstrado discursivamente por onde passa o que se diz sobre os elos entre a docência e a arte. Parece que vem sendo atribuído à docência em artes visuais um modo fixado em um tal fazer arte, tomado como exemplo, que impede existências singulares com a arte. É a inexistência de uma prática exemplar das professoras como artistas, na qual o objeto artístico seria produzido ou, ao menos, exercitado, o que constrói os efeitos de anulação, perda e dívida para com a arte.

A ligação entre professor e artista, atualmente, é um discurso que chega ao sujeito docente como parte de um conjunto de recomendações que até extrapolam a docência em artes visuais. Demonstramos que certos ditos sobre professor-artista propõem um estado de ser que alimenta, por um lado, o talento e a intuição pedagógica e, por outro, a capacidade de criação performática de professores (CAPRA; LOPONTE, 2016). Além de dirigir as suas condutas, sugerem uma moralidade utilitária para a arte. Especificamente na docência em artes visuais, a recomendação para que professores sejam artistas pode ser acompanhada pelo que propõe o Instituto Arte na Escola, que mantém um programa de formação e apoio pedagógico para o ensino de arte no Brasil desde o final da década de 1980. Faz poucos anos, foi aberta no site institucional a página "Galeria dos Professores-Artistas", um espaço para mostrar a produção pessoal de quem, além da docência, também se dedica à produção artística. Nesse caso, a produção individual vem explicada - e também conduzida 
- desta forma: "O fazer artístico fortalece as práticas do professor em sala de aula, e o diálogo entre a criação poética e a pedagógica provoca um olhar mais sensível e atento para os alunos" (INSTITUTO ARTE NA ESCOLA, 2015. Grifos nossos).

No mesmo sentido, um grupo de professores vinculado ao mesmo instituto desenvolveu um projeto que "tinha como objetivo geral compreender como se dão os processos de criação na poética pessoal dos professores com formação em Artes Visuais que abandonaram sua produção em função do magistério" (TINOCO, 2013, p. 3. Grifo nosso). O projeto propôs-se a "Pensar o professor de arte como um fazedor de arte e propiciar meios para que isso se realize", porque supunham um "desejo de produzir" que estaria "esquecido e/ou adormecido desde o tempo da graduação" (TINOCO, 2013, p. 10).

Tal descrição autoriza uma relação com a potência quando tomada por uma faculdade do sujeito e que é mobilizada por necessidade ou por vontade, sendo esses mesmos elementos os que compõem o que se diz sobre os professores que não avançaram em "no ser" artistas porque:

[...], alguns professores não conseguiram ir além dos exercícios. Entre as prováveis barreiras, pode estar o não comprometimento, ou envolvimento com o projeto: professores que não ficam o tempo estipulado, que faltam a alguns encontros, que usam o espaço para conversarem sobre outros assuntos, etc. Podemos considerar que esses professores se encontram envolvidos prioritariamente com a prática pedagógica não encontrando tempo para uma proposta poética como artista. Outra questão que se coloca: o professor quer ser artista? Podemos nos deparar com uma realidade onde professores queiram ser professores-artistas e outros se sintam bem somente como professores. (TINOCO, 2013, p. 10. Grifos nossos).

É evidente a relevância dos que lecionam artes visuais também se dedicarem a pensar artisticamente e participarem de exposições. Todavia, é preciso acentuar de que são feitos os argumentos que, versando sobre a conduta dos indivíduos, analisam-nos pelos parâmetros morais de disposição, persistência, envolvimento e vontade. É um tipo de governo que gira em torno de um modo de ser artista de contornos precisos, onde inexistem as formas da arte como potência. O docente pode, deve, fazer arte? Skliar contribui com uma ideia que abre as palavras: "Pode' não é poder, é tremor, é quase, é talvez" (SKLIAR, 2014, p. 146).

Propomos levantar uma suspeita acerca dos aconselhados modos de existir artisticamente na docência em artes visuais. Retomando os ditos das professoras, a aula e o fazer arte delas estão separados e a arte não se efetiva a contento. Escamando a significação dos ditos, são dois objetos e dois sujeitos diferentes: a arte produzida pelo professor não é aquela da aula ministrada; quem leciona na escola não consegue manter uma prática artística. A arte dessa relação com a docência está em outro lugar ou condição, pois não parece dar-se no mesmo instante da docência. 
A arte que seria feita com meios e modos específicos, do professor quando artista, remete à distribuição de funções exteriores à arte, como tornar mais sensível quem dá aulas, e à incompatibilidade com o seu bom ensino a com própria docência. Arriscamos dizer que, pelas práticas discursivas que compõem o que professoras dizem da sua relação com a arte, há um endividamento duplo: há que existirem artisticamente, mas isso encontra grandes dificuldades em se realizar nos termos exemplares colocados para a arte. Parafraseando Skliar (2014), entendemos que, ao redor da docência em escolas, deveria haver toda existência em relação à arte.

\section{DESVIOS OU AFROUXAMENTOS PARA QUE EXISTA TODO ESTADO ARTÍSTICO}

A este ponto, entendemos que é necessário manejar o pensamento sobre os elos que fabricamos entre a arte e a docência em artes visuais, seja em formação nas licenciaturas, seja em exercício nas escolas. Ao observar as palavras de ordem em circulação - professoras (não) podem, (não) devem ou (não) querem praticar a arte pelos modos prescritos -, há que observar também as possibilidades de resistências e descontinuidades nos processos de regulação da subjetividade. Foucault (2001) propõe romper com o jogo dos reconhecimentos para deixar existir descontinuidades nos modos de ser, sem que isso signifique voltar a identidades primordiais, exemplarizadas.

As práticas que estão entre o preparo ou o exercício da docência e as artes visuais, quando adotadas como verdades, estabelecem poderes e dominações, por isso nosso intento em problematizar as relações com a arte que vão sendo dispostas exemplarmente, como "seres-ditos", pelo modo biográfico e autoral disseminado pela história e crítica da arte, o modo exemplar do artista em produzir arte e até os meios de legitimação que devem ser acionados para seus trabalhos serem reconhecidos como arte. São fios da trama discursiva ordenadora do que seriam o trabalho e o ser docente em artes visuais que, no entanto, podem produzir ecos morais nos sujeitos.

Para não apenas estacionar na identificação das ordens que nos assolam, passamos a reconhecer singularidades e outras perspectivas. Retomamos, então, a história da arte na formação docente na licenciatura. Como disciplina, a história da arte alcançou a posição de indispensabilidade e crescente refinamento, capaz de vir definindo, a alguns séculos, quem é e o que faz o artista (DIDI-HUBERMAN, 2013a). Na formação universitária, esse campo de verdade, entre outros, vai compondo possibilidades de ser e de agir para os acadêmicos em relação à arte. São lugares ou funções que direcionam ou mesmo desenham experiências formativas, na licenciatura: especialistas em história, espectadores, artistas, mediadores da aprendizagem dos alunos, propositores e, até mesmo, curadores. Isso permite observar que, na medida em que as articulações entre a formação artística e a formação docente são pautadas por definições do campo artístico, elas delineiam "licenças" ou permissões, modos de ser e de agir aos futuros professores em relação à arte. 
Larrosa (2014) põe em evidência a condução dos modos de ser e agir de professores quando fala de justificações elaboradas para o campo educativo, começando pela vocação dos professores, depois o alinhamento à retórica humanista, mais tarde, as competências técnico-científicas que os equiparavam aos médicos e engenheiros, passando à aquisição de uma consciência reflexiva.

E vamos ver se agora vão mandar que identifiquemos e elaboremos nossa experiência pessoal. Isso seria converter a experiência em um fetiche e em um imperativo, como são um fetiche e um imperativo o signo zodiacal, a alma, a identidade profissional, a cultura, a ideia de homem, a vocação, a consciência crítica, o inconsciente e todas essas coisas que nos dizem que temos embora não saibamos, que nos dizem que deveríamos ter mesmo que nunca tenhamos sentido a necessidade, e que nos dizem que temos que aprender a buscar, a reconhecer e a elaborar. (LARROSA, 2014, p. 45. Grifos nossos).

É propriamente a elaboração da experiência pessoal o que vem emergindo para a docência em artes visuais, com ares de fetiche e de uma imprescindibilidade que busca mostrar-se como, desde sempre, uma necessidade. Nitzscheanamente pensando, as "verdades verdadeiras" do campo artístico simplificam a complexidade própria da arte e planificam a docência em artes visuais na educação básica. Podem vir a restringir a ação de professoras e professores ao ponto de implementar, como se vê em alguns ditos, um dever pautado por "força ou fraqueza, riqueza ou pobreza, excesso ou falta", para usar os termos de Machado (2002) e que, além disso, introduzem uma insuficiência permanente, no caso dos ditos trazidos a este ensaio, sobre o afastamento (ou uma necessária aproximação) em relação à arte. Os valores atribuídos à arte, ao artista, ao professor e às maneiras de entender a potência artística aí envolvida estabelecem verdades que distribuem pesos e medidas. Se tomados como determinações, empobrecem a criação de outros modos de fazer arte na docência, isto é, outros modos de existir artisticamente na docência em artes visuais.

Com Skliar (2014, p. 149), buscamos desobedecer a linguagem, e

[...] desestimar qualquer ideia ou vestígio de normalidade, de hábito, do encolhimento de ombros que significa que as coisas são assim mesmo. Ali é onde morre parte do mundo e, também, parte de nós mesmos.

Desviar das existências artísticas difundidas ou criar outras é uma motivação de nuança foucaultiana que não atenta a quem fala, mas à substância fina presente no que é dito. Por isso, os discursos que circulam entre os dizeres são muito importantes: lecionar e fazer arte são incompatíveis, mas professoras de Arte devem ser artistas. Se o forem, tornam-se melhores professoras, rendendo um ganho para a profissão sempre considerada 
deficitária. Além disso, na escola não é possível ensinar arte de verdade às turmas. Nesses casos, o sujeito da docência forma e é formado por um campo de batalha discursivo com a arte, onde, ora se diz do seu afastamento da arte, ora se the induz a ela, mas sempre com aguda tensão sobre o sujeito. É interessante perceber que um mesmo modo de produção de arte e de conhecimento artístico parece estar em pauta, remetendo à produção individual e não compartilhável que culmina no objeto artístico e sobre o que é legitimado e descrito pela história e a crítica da arte. É um modo bastante específico de ser artista, no qual a sua prática é tomada como exemplo para as práticas docentes com a arte, mas que ignora tanto a arte que se faz na escola, entre quem ensina e quem aprende arte, quanto a fertilidade daquele lugar para produzir existências artísticas nas formas que tiverem.

Não será disputando tempos entre a arte e a docência que os professores conciliarão as duas áreas, inclusive pensamos que não é esse o caso: o modo de produzir arte calcado no que é afirmado pelo campo artístico tem uma validade questionável para o que é próprio à docência, porque a educação em artes visuais tem uma agenda própria que é ampla, porém específica. Por conta disso, como professoras formadoras em licenciaturas em artes visuais, precisamos indagar sobre o que caracteriza as relações com a arte difundidas para a formação e para a atuação docente em artes visuais em escolas. Essa questão precisa ser aberta à discussão em uma tentativa de apresentar a multiplicidade do visível e do enunciável e dos modos de subjetivação (FISCHER, 2012) existentes, a fim de rastrear o que compõem as modulações prescritas e as que estão por serem inventadas entre docência e artes visuais.

Sistemas de verdade - história, arte, educação, por exemplo - devem a sua razão a um conjunto de agentes que distinguem, repartem e dispersam os acontecimentos do mundo. Vêm deles períodos, estilos, estágios e modos de ser e de agir, validando operações com a arte que compõem a formação docente e estabelecendo certos modos (ou modos certos) de organização das coisas e dos sujeitos da licenciatura em artes visuais.

Não obstante as "soberanias" que sustentam valores e modos de ser professor, podem ocorrer aberturas pelas quais emerjam as resistências e as descontinuidades negligenciadas no processo de formação dos sistemas de verdade, mas também aquilo que insurge pelos sujeitos em processos de educação. As posições propagadas a respeito da arte são construções que podem manter-se no nível do cânone também para a educação em artes visuais a ser desenvolvida nas escolas. Caso a licenciatura em artes visuais acate o que vem da esfera da arte na formação artística e na formação pedagógica de professores, pode ser que a experiência com arte, na escola, seja uma extensão dos sistemas de verdade, restringindo o caráter informe da arte, como aquilo que sempre está por gerar forma. Ademais, quando professores entendem-se em posições marcadas, ora na docência, ora na arte, perguntamos se não estariam realizando uma separação que deixa de movimentar os limites da educação escolar e da própria arte, tarefa condizente com o que constitui a relação do professor com o seu campo de saber. 
Há poucas chances da formação docente em artes visuais partir de outros campos que não sejam os academicamente delimitados nas suas bases e, neste artigo, não se pretende atuar por invalidação ou negação da academia. A partir das demarcações existentes para arte e para educação, buscamos tensionar os lugares ocupados pelo sujeito docente em relação à arte, no entanto, o curso de licenciatura em artes visuais pode ser menos o fixador de destinos, de onde advém efeitos de obrigação, incapacidade, insuficiência, dívida em relação à arte, e ser mais um terreno fértil para modalidades nascentes de ser professores de artes visuais. Seriam modos de ser "entre a ontologia e a ética", pela ideia de Agamben (2013), de um ser:

[...] que não se pressupõe a si como uma essência escondida, que o acaso ou o destino empurraria então para o suplício das qualificações, mas se expõe nelas, é, sem resíduos, o seu assim. Um tal ser não é nem acidental nem necessário, mas é, por assim dizer, continuamente gerado a partir da própria maneira. (AGAMBEN, 2013, p. 35. Grifos do autor).

A ideia é, na formação e na atuação docente, produzir estatutos artísticos que não se restrinjam aos articulados pelos sistemas de verdade da arte ou que sejam controlados por operações de poder sobre a potência de professores. A proposta é buscar estados artísticos como espaços de verdade (não da verdade), evidentemente, não pelos motivos já questionados, mas porque tais estados artísticos seriam verdadeiros na medida em que não se sobrepõem ao sujeito (AGAMBEN, 2013) e, no interior das relações entre arte e educação, dariam lugar ao seu assim..

Está em funcionamento uma concepção agambeniana: "não a produção de arte justificada pela metafísica da vontade", do gênio ou da força criativa, mas a arte como pro-dução, poíesis. Significa trazer algo à existência que reside na produção de uma verdade que necessariamente faça uma abertura na direção de "um mundo para a existência e a ação do homem" (AGAMBEN, 2012, p. 121). Exposto em outras palavras, visamos a produção de contextos onde seja possível aos professores existirem artisticamente na forma própria da sua potência. Talvez essa seja a condição ontológica e ética que poderá compor a licenciatura e, mais adiante, contribuir para a educação escolar em artes visuais. 


\section{REFERÊNCIAS}

AGAMBEN, Giorgio. Bartleby, ou da contingência. Tradução de Vinícius Honesko. Belo Horizonte: Autêntica, 2015a.

. A Potência do Pensamento: ensaios e conferências. Tradução de António Guerreiro. Belo Horizonte: Autêntica, 2015b.

Nudez. Tradução de Davi Pessoa Carneiro. Belo Horizonte: Autêntica, 2014.

A comunidade que vem. Tradução de Cláudio Oliveira. Belo Horizonte: Autêntica, 2013.

O homem sem conteúdo. Tradução de Cláudio Oliveira. Belo Horizonte, Autêntica, 2012.

BRASIL. Diretrizes Curriculares Nacionais para a formação inicial em nível superior (cursos de licenciatura, cursos de formação pedagógica para graduados e cursos de segunda licenciatura) e para a formação continuada. Ministério da Educação. Conselho Nacional de Educação. Conselho Pleno: Brasília, 2015. Disponível em: <http://migre.me/vbQaJ>. Acesso em 9 jul. 2016.

Referenciais Curriculares Nacionais dos Cursos de Bacharelado e Licenciatura. Ministério da Educação. Secretaria de Educação Superior: Brasília, 2010. Disponível em: <http://www. castelobranco.br/site/arquivos/pdf/Referenciais-Curriculares-Nacionais-v-2010-04-29.pdf>. Acesso em 9 jul. 2016.

Ministério da Educação. Plano Nacional de Formação dos Professores da Educação Básica. Censo do Professor: Rio Grande do Sul. 2007. Disponível em <http://portal.mec.gov.br/plano-nacional-de-formacao-de-professores/censo-do-professor>. Acesso em 5 out. 2016.

CAPRA, Carmen Lúcia. Conhecer, conectar-se, produzir: diferentes vínculos entre a docência em artes visuais e a arte. In: Anais do I Seminário Nacional Formação Pedagógica e Pensamento Nômade: experimentações curriculares, 2015, Lajeado, RS. Lajeado: Ed. da Univates, 2015. Disponível em <https://www.univates.br/editora-univates/media/publicacoes/125/pdf_125.pdf>. Acesso em 5 dez. 2016.

; LOPONTE, Luciana Gruppelli; MOMOLI, Daniel Bruno. Para pensar o horizonte da arte e da educação na contemporaneidade. Revista GEARTE, [S.I.], v. 3, n. 2, ago. 2016. ISSN 2357-9854. Disponível em: <http://seer.ufrgs.br/index.php/gearte/article/view/65911>. Acesso em: 08 dez. 2016b.

Ditos sobre professor-artista. In: Reunião Científica Regional da ANPED, XI, Curitiba, PR. Educação, movimentos sociais e políticas governamentais, 2016. P. 1-15. Disponível em <http://www.anpedsul2016.ufpr.br/trabalhos-completos-eixo-6-formacao-deprofessores/>. Acesso em 25 dez. 2019.

DIDI-HUBERMAN, Georges. Diante da imagem. Tradução de Paulo Neves. São Paulo: 34, $2013 a$.

A imagem sobrevivente: história da arte e tempo dos fantasmas segundo Aby Warburg. Tradução de Vera Ribeiro. Rio de Janeiro: Contraponto, 2013b. 
FISCHER, R. M. B. Trabalhar com Foucault: arqueologia de uma paixão. Belo Horizonte: Autêntica, 2012.

FOUCAULT, Michel. Nietzsche, a genealogia e a história. In: Microfísica do poder. Tradução de Roberto Machado. Rio de Janeiro: Graal, 2001. p. 15-37.

Verdade e subjectividade (Howison Lectures). Revista de comunicação e linguagem. $\mathrm{n}^{\circ} 19$. Lisboa: Edições Cosmos, 1993. p. 203-223. Disponível em <https://pt.scribd.com/doc/138852715/ Foucault-Subjetividade-e-Verdade>. Acesso em 5 out. 2016.

GATTI, Bernardete Angelina. Formar professores: os dilemas de formação e a educação escolar em artes. In: Anais do Simpósio Internacional: formação de educadores em arte e pedagogia, Universidade Presbiteriana Mackenzie, 2015. São Paulo: Terracota, 2015.

; BARRETO, Elba Siqueira de Sá, ANDRÉ, Marli Eliza Dalmazo de Afonso. Políticas Docentes no Brasil: um estado da arte. Brasília: UNESCO, 2011.

GOMBRICH, Ernst. A História da Arte. Rio de Janeiro: Guanabara Koogan, 1993.

INSTITUTO ARTE NA ESCOLA. Galeria dos Professores-Artistas. Disponível em <http://artenaescola.org.br/galeria-dos-professores/>. Acesso em 9 nov. 2016.

LARROSA, Jorge. Tremores: escritos sobre experiência. Tradução de João Wanderley Geraldi, Cristina Antunes. Belo Horizonte: Autêntica, 2014.

MACHADO, Roberto. Nietzsche e a Verdade. São Paulo: Graal, 2002.

MOMOLI, Daniel Bruno. Arte e formação estética docente. In: Reunião Científica Regional da ANPED, XI, Curitiba, PR. Educação, movimentos sociais e políticas governamentais, 2016. Disponível em <http://www.anpedsul2016.ufpr.br/trabalhos-completos-eixo-19-educacao-e-arte/>. Acesso em 3 ago. 2016.

NIETZSCHE, F. A gaia ciência. São Paulo: Companhia das Letras, 2012.

SILVA, Everson Melquíades Araújo. A formação do arte/educador: um estudo sobre história de vida, experiência e identidade. 2010. 285f. Tese (Doutorado em Educação). Universidade Federal de Pernambuco. Recife, 2010.

SKLIAR, Carlos. Desobedecer a linguagem: educar. Belo Horizonte: Autêntica, 2014.

RIO GRANDE DO SUL. Secretaria da Educação. Censo escolar 2014. Disponível em <http://www. educacao.rs.gov.br/pse/html/estatisticas.jsp?ACAO=acao1>. Acesso em 5 out. 2016.

TINOCO, Eliane de Fátima Vieira. Projeto professor-artista no polo UFU da rede arte na escola. 2013. Disponível em <http://artenaescola.org.br/sala-de-leitura/artigos/artigo. php?id=72145>. Acesso em 5 dez. 2016.

VASARI, Giorgio. Vidas dos artistas. Tradução de Ivone Castilho Benedetti. São Paulo: WMF Martins Fontes, 2011.

VEYNE, Paul Marie. Como se escreve a história. Foucault revoluciona a história. Tradução de Alda Baltar e Maria Auxiliadora Kneipp. Brasília: Universidade de Brasília, 1998. 